\title{
Fabrication of Polyelectrolyte Multilayer Films Comprising
}

\author{
Nanoblended Layers \\ Jinhan Cho, John F. Quinn and Frank Caruso* \\ Centre for Nanoscience and Nanotechnology, Department of Chemical and Biomolecular \\ Engineering, The University of Melbourne, Victoria 3010, Australia.
}

\section{Supplementary Information}

Materials. Poly(acrylic acid, sodium salt) (PAA, $\mathrm{M}_{\mathrm{w}}=2000,30000$ and $250000 \mathrm{~g} \mathrm{~mol}^{-1}$ ) and poly(allylamine hydrochloride) $\left(\mathrm{PAH}, \mathrm{M}_{\mathrm{w}}=70000 \mathrm{~g} \mathrm{~mol}^{-1}\right)$ were obtained from Sigma Aldrich and used as received. Poly(styrenesulfonate, sodium salt) (PSS, $\mathrm{M}_{\mathrm{w}}=70000 \mathrm{~g} \mathrm{~mol}^{-1}$ ) was also obtained from Aldrich and dialyzed against pure water and lyophilized prior to use. Hydrochloric acid, sodium hydroxide and sodium chloride were obtained from BDH and used as received. High purity water with a resistivity greater than $18 \mathrm{M} \Omega \mathrm{cm}$ was obtained from an inline Millipore RiOs / Origin system. Quartz substrates were purchased from Hellma Optik $\mathrm{GmbH}$ (Jena, Germany), silicon wafers from Silchem Handelgesellschaft mbH (Germany) and QCM electrodes from Kyushu Dentsu (Nagasaki, Japan).

Quartz slides were cleaned with Pirahna solution (70/30 v/v\% sulfuric acid: hydrogen peroxide). Caution! Piranha solution is highly corrosive. Extreme care should be taken when handling piranha solution and only small quantities should be prepared. Quartz slides were further cleaned and hydrophilized by treatment with RCA solution (5:1:1 water: ammonia: hydrogen peroxide) at $60{ }^{\circ} \mathrm{C}$. The silicon wafers were cleaned by using isopropanol and hydrophilized with a RCA solution (sonication in a 1:1 mixture of water and isopropanol for $15 \mathrm{~min}$, followed by heating at $70{ }^{\circ} \mathrm{C}$ for $10 \mathrm{~min}$ in a 5:1:1 mixture of water, $\mathrm{H}_{2} \mathrm{O}_{2}$, and 29 vol $\%$ ammonia solution) for $15 \mathrm{~min}$ at $60{ }^{\circ} \mathrm{C}$.

All solutions were prepared to a concentration of $1 \mathrm{mg} \mathrm{ml}^{-1}$, and the $\mathrm{pH}$ was adjusted using $\mathrm{HCl}$ or $\mathrm{NaOH}$. The $\mathrm{pH}$ of each solution was measured with a Mettler-Toledo MP220 $\mathrm{pH}$ meter.

Methods. Quartz Crystal Microgravimetry: The resonance frequency of the QCM electrodes was ca. $9 \mathrm{MHz}$. Assuming the film density of PEs is $1.2 \times 10^{6} \mathrm{~g} \mathrm{~m}^{-3}$, the adsorbed PE mass, $m$, can be calculated from the change in QCM frequency, $\Delta F$, according to the equation $\Delta F(\mathrm{~Hz})$ $=-1.15 \times \Delta m(\mathrm{ng})$, where $m$ is the mass change per quartz crystal unit area in $\mathrm{g} \mathrm{m}^{-2}$. See for 
example, Caruso, F.; Niikura, K.; Furlong, D. N.; Okahata, Y. Langmuir 1997, 13, 3422.

Ellipsometry: The film thicknesses adsorbed onto silicon wafers were with a Gaerter Ellipsometer equipped with a He-Ne laser $(\lambda=632.8 \mathrm{~nm})$. In the data fitting procedure, the refractive index was allowed to using an iterative process.

Infrared Spectroscopy: FTIR measurements were performed with a JASCO FT/IR 200 spectrometer operating in reflection mode. Glass slides coated initially with chromium $(5 \mathrm{~nm})$ and then with a gold layer $(120 \mathrm{~nm})$ were used as substrates.

Calculation of \%PSS in films: Based on the frequency change of QCM and absorbance peak area of PSS layers assembled from PSS $100 \mathrm{wt} \%$, the amount of adsorbed PSS in the blended layers was calculated. The absorbance peak area of PSS was calculated by the GaussianLorentz method.

UV - Visible Spectrophotometry: UV-visible spectra were collected using an Agilent 8453 Single Beam UV-visible spectrophotometer.

Atomic Force Microscopy. AFM images were taken using a Nanoscope IIIA atomic force microscope in tapping mode on air-dried films. The scan areas were $30 \mu \mathrm{m} \times 30 \mu \mathrm{m}$ or $10 \mu \mathrm{m}$ $\times 10 \mu \mathrm{m}$.

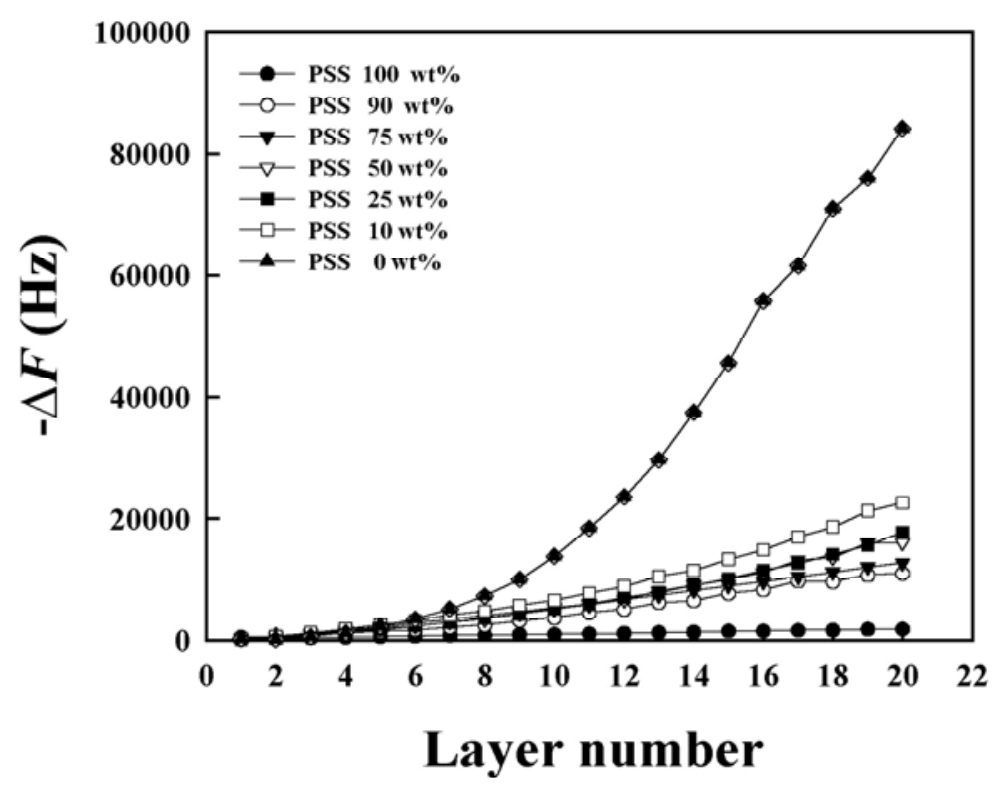

S1a. QCM frequency changes for $\left(\mathrm{PAH} / \mathrm{blend}_{10}\right.$ multilayer films with varying blend compositions. $\mathrm{PAH}$ solution $\mathrm{pH}=7.5$, blend solution $\mathrm{pH}=3.5,[\mathrm{NaCl}]=0.5 \mathrm{M}$, and $\mathrm{M}_{\mathrm{w}}$ (PAA) $30000 \mathrm{~g} \mathrm{~mol}^{-1}$. 


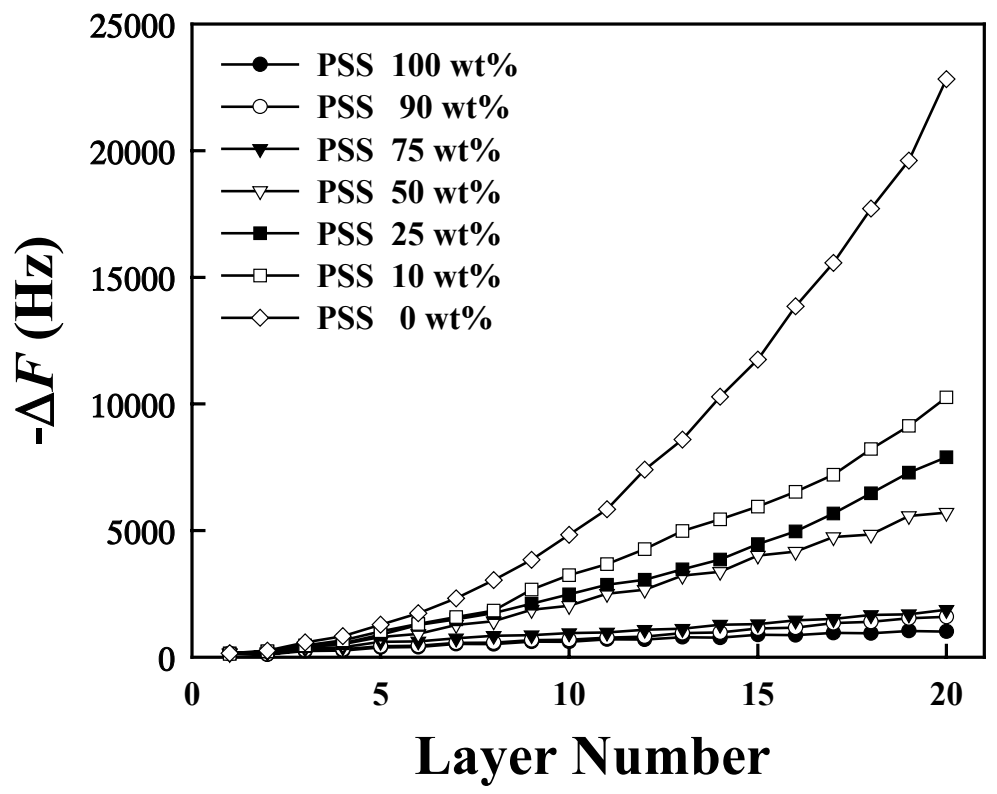

S1b. QCM frequency changes for $(\mathrm{PAH} / \mathrm{blend})_{10}$ multilayer films with varying blend compositions. $\mathrm{PAH}$ solution $\mathrm{pH}=7.5$, blend solution $\mathrm{pH}=3.5,[\mathrm{NaCl}]=0 \mathrm{M}$, and $\mathrm{M}_{\mathrm{w}}(\mathrm{PAA})$ $\sim 2000 \mathrm{~g} \mathrm{~mol}^{-1}$.

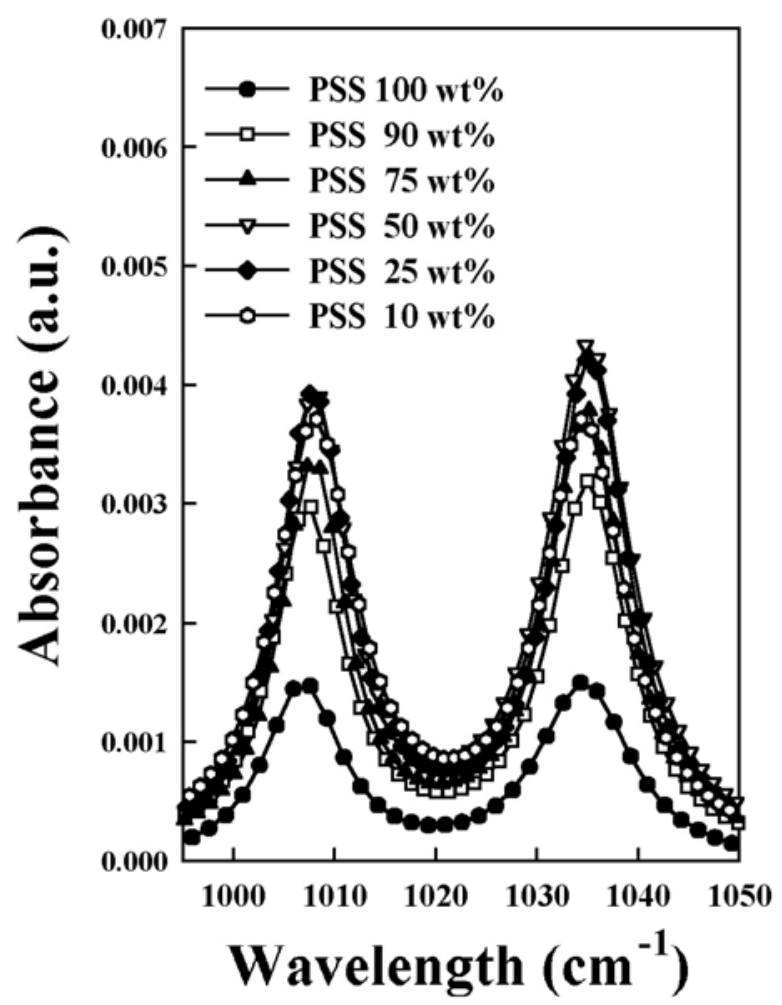

S2. FTIR absorbance spectra of $(\mathrm{PAH} / \mathrm{blend})_{10}$ multilayer thin films with varying blend composition. $\mathrm{PAH}$ solution $\mathrm{pH}=7.5$, blend solution $\mathrm{pH}=3.5$, $[\mathrm{NaCl}]=0 \mathrm{M}$, and $\mathrm{M}_{\mathrm{w}}(\mathrm{PAA}) \sim$ $30000 \mathrm{~g} \mathrm{~mol}^{-1}$. 


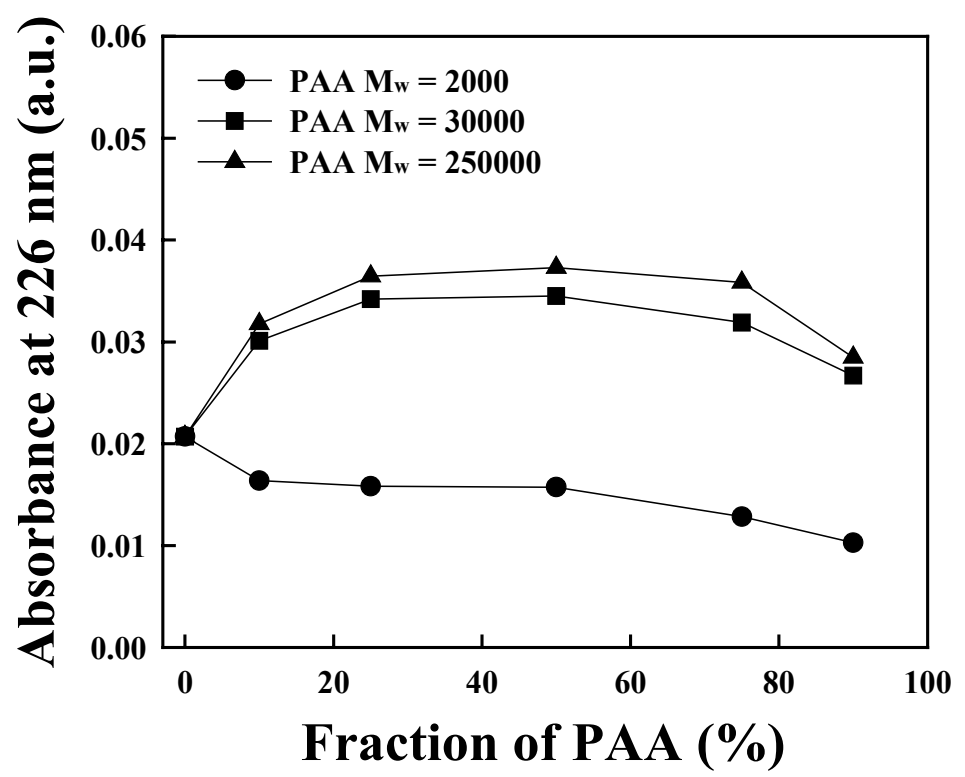

S3. UV-visible absorbance per bilayer at $226 \mathrm{~nm}$ for $(\mathrm{PAH} / \mathrm{blend})_{10}$ multilayer films with varying blend compositions. $\mathrm{PAH}$ solution $\mathrm{pH}=7.5$, blend solution $\mathrm{pH}=3.5,[\mathrm{NaCl}]=0 \mathrm{M}$, and $\mathrm{M}_{\mathrm{w}}$ of PAA 2000,30000 and $250000 \mathrm{~g} \mathrm{~mol}^{-1}$.

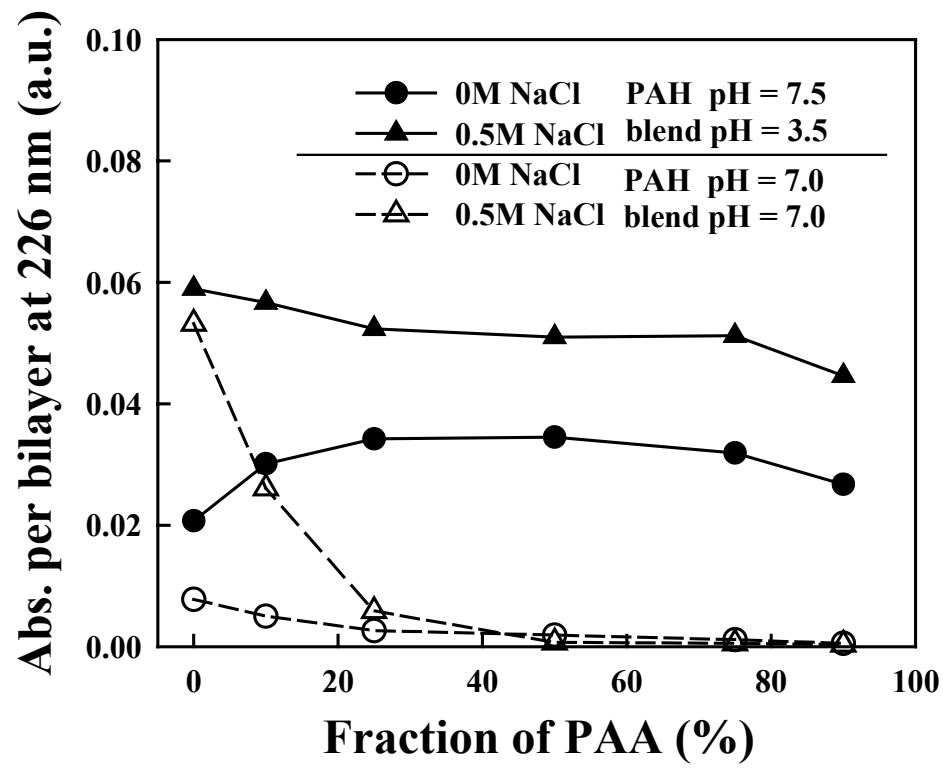

S4. UV-visible absorbance per bilayer at $226 \mathrm{~nm}$ for (PAH/blend) ${ }_{10}$ multilayer films with varying blend compositions. $[\mathrm{NaCl}]=0.5 \mathrm{M}$. PAH solution $\mathrm{pH}=7.5 / 7.0$, blend solution $\mathrm{pH}=3.5 / 7.0$, and $\mathrm{M}_{\mathrm{w}}(\mathrm{PAA}) \sim 30000 \mathrm{~g} \mathrm{~mol}^{-1}$. 